\title{
A simple methodology for sinusoidal oscillator design based on simulation of differential equation using AD844 configured as second-generation current conveyor
}

\author{
Anwar A. Khan ${ }^{1}$, Sadanand Bimal ${ }^{2}$, K. K. Dey ${ }^{3}$ and S. S. Roy ${ }^{3}$ \\ ${ }^{1}$ Vice - Chancellor, Ranchi University, Ranchi-834008, India \\ ${ }^{2}$ Dept. of Physics, B. I. T. Sindri-828123, Dhanbad (Jharkhand), India \\ ${ }^{3}$ Electronics laboratory, University department of physics, R. U. Ranchi-834008, India. \\ sn_bimal@yahoo.com; khananwar2k7@gmail.com
}

\begin{abstract}
The work presented in the paper develops a methodology for the design of sinusoidal oscillator based on simulation of differential equation using second generation current conveyors. A practical circuit using the IC AD844 configured as current conveyor (CCII+) with CMOS analog switch DG201 illustrates the methodology. Experimental results are given. The scheme is suitable for frequencies below $1 \mathrm{MH}_{\mathrm{z}}$.
\end{abstract}

Keywords: Current conveyor, IC AD844, sinusoidal waveform generation, RC oscillator.

\section{Introduction}

Generation of sinusoidal function is a common problem encountered by circuit designers (Singh, 1980). Sinusoidal signal generators are required in a number of diverse areas including audio testing, calibration equipment, transducer drives, power conditioning and automatic test equipment (ATE). Control of frequency, amplitude or distortion level is often required and all three parameters must be simultaneously controlled in many applications. A number of techniques utilizing both analog and digital approaches are available for a variety of applications. Each individual circuit approach has inherent strength and weakness, which must be matched against any given applications. Among the methods used for generating sinusoidal waveform, the method used to simulate second order differential equation has received almost no attention. In this paper, a simple design methodology for the realization of stable sinusoidal function over a wide dynamic range based on the simulation of second order differential equation using second generation current conveyor is described, analyzed and studied experimentally.

Methodology and design

The design methodology is simple, straight and offers quality sinusoidal waveform over a range of frequency.

The sinusoidal waveforms with a peak amplitude $\mathrm{E}$ and angular frequency $\omega$ as described by:

$$
V=E \cdot \cos \omega \cdot t
$$

or

$$
V=E \cdot \sin \omega \cdot t
$$

are the solution of second order differential equation of the form

$$
\frac{d^{2} V}{d t^{2}}+\omega^{2} V=0
$$

with the initial condition imposed. For e.g., eq. (1) is the solution of equation (3) provided

$$
\left.\begin{array}{l}
\left.\frac{d V}{d t}\right|_{t=0}=0 \\
\text { and } \\
\left.V\right|_{t=0}=E
\end{array}\right\}
$$

Similarly, eq. (2) is the solution of eq. (3) provided

$$
\left.\begin{array}{l}
\left.\frac{d V}{d t}\right|_{t=0}=\omega E \\
\text { and } \\
\left.V\right|_{t=0}=0
\end{array}\right\}
$$

In principle, the eq. 3 can be implemented as illustrated (Fig. 1) to provide sinusoidal output waveforms under different sets of initial conditions as documented in eq. 4 and eq.5. The implementation of the initial conditions in eq. 4 is easy and straight forward compared to that documented in eq. 5 as the initial conditions attached with eq. 5 are frequency dependent. This suggests that circuit implementation of eq. 3 with eq. 4 which yields sinusoidal waveform as in eq. 1 is somewhat easy and deserves further investigations.

The voltage mode operational amplifiers (op amp) configured as an integrator (Fig. 2) may be used to implement the scheme as depicted in (Fig.1). However, the integrator as shown in (Fig. 2) poses a problem in applying the initial condition as the capacitor is floating. Moreover, floating capacitor is not preferred in IC design methodology. In recent past second generation current conveyor (CCII), because of its attractive features, has been widely used in circuit design (Wilson, 1990; Sedra et al., 1990; Toumazou et al., 1990). It is now well known that IC AD844 from analog devices implements the features of positive second generation current conveyor (CCll+) with an additional unity gain voltage amplifier (Svoboda et al., 1991). The circuit symbol of AD844 (Khan Anwar et al., 2002; Khan Anwar et al., 2005)
Research article

CIndian Society for Education and Environment (iSee)
"Sinusoidal oscillator" http://www.indjst.org
Anwar A.Khan et al. Indian J.Sci.Technol. 
Indian Journal of Science and Technology

Fig. 1. Scheme for implementation of second order differential equation with no damping

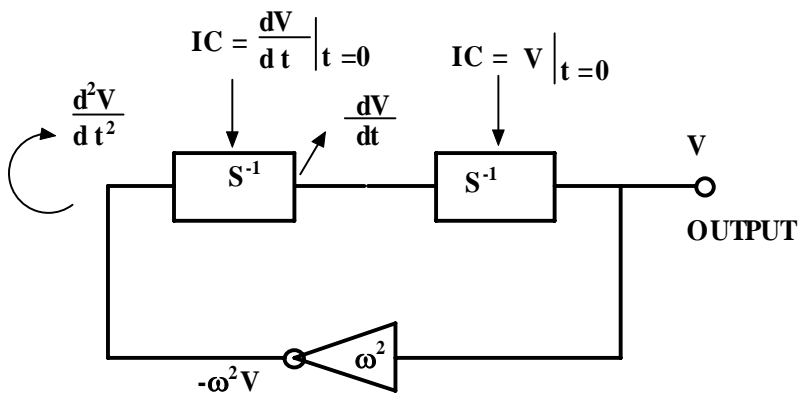

Fig. 3. Equivalent circuit symbol of IC AD844

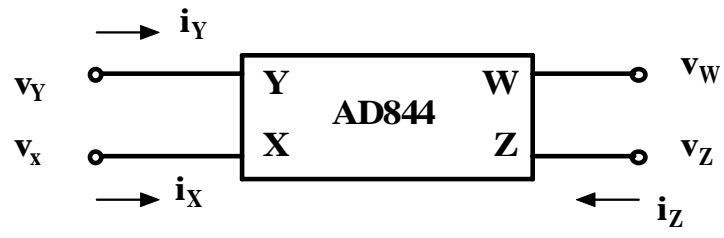

Fig. 5. Proposed current conveyor (AD844) based scheme for the generation of sinusoidal wave form

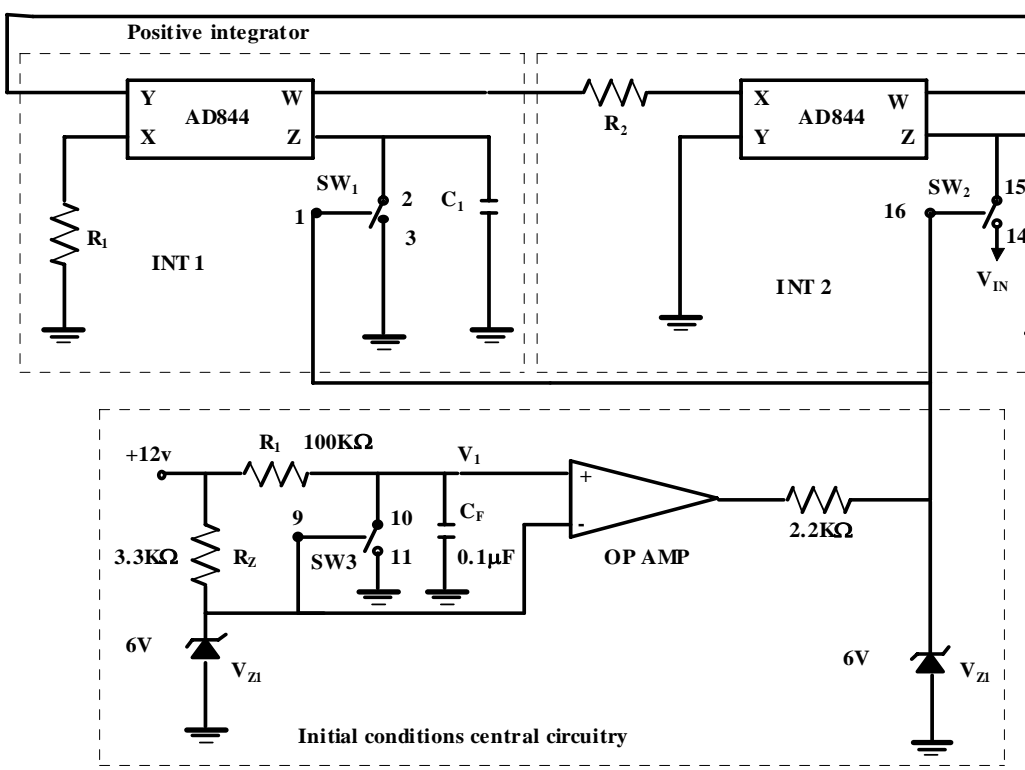

Supply volt ages to AD844 and op amp are $\pm 12 \mathrm{v}$

Fig.6. Oscillograms showing the oscillations at frequencies $8 \mathrm{KHz} \& 227 \mathrm{KHz}$ respectively.
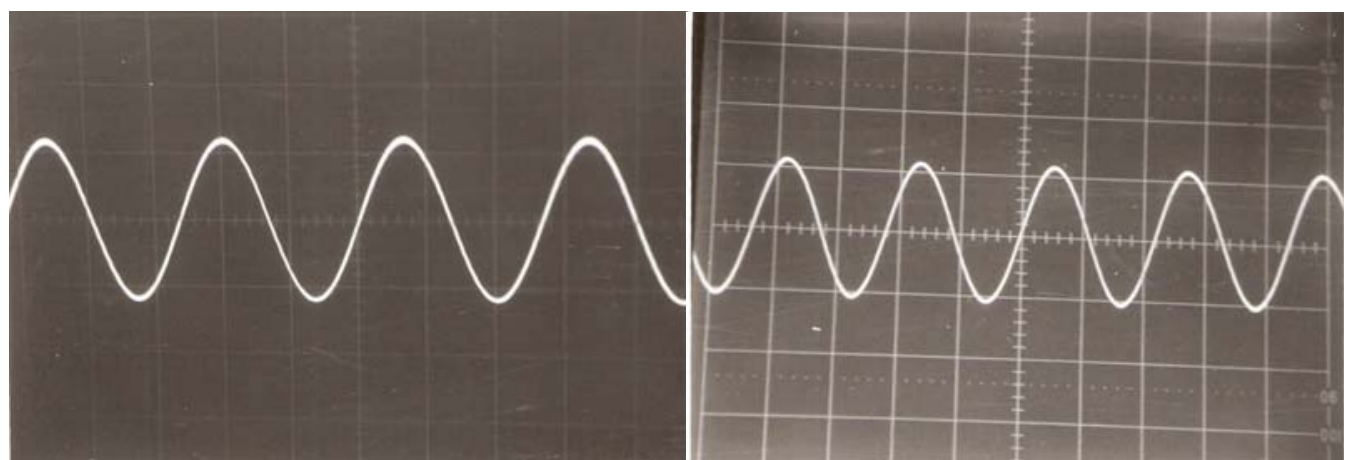

Research article

CIndian Society for Education and Environment (iSee)
"Sinusoidal oscillator" http://www.indjst.org
Vol. 3 No. 6 (June 2010)

ISSN: 0974- 6846

Fig. 2. A typical op amp based integrator

Fig. 4. AD844 based integrator
(a). Positive integrator
(b). Negative integrator

Initial condition control

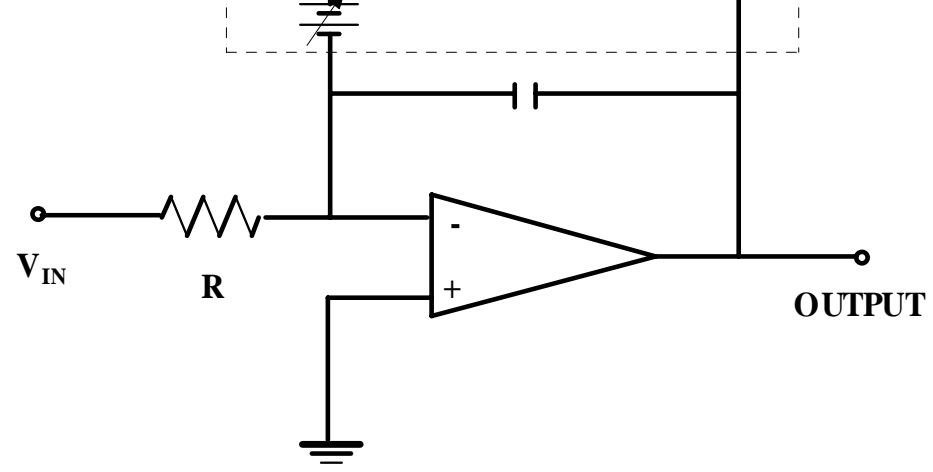

$\mathbf{V}_{\text {in }}$

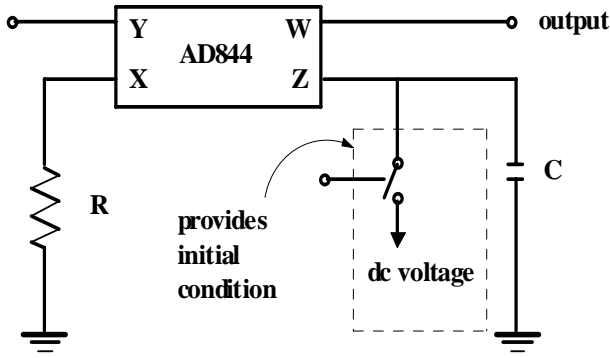

(a)

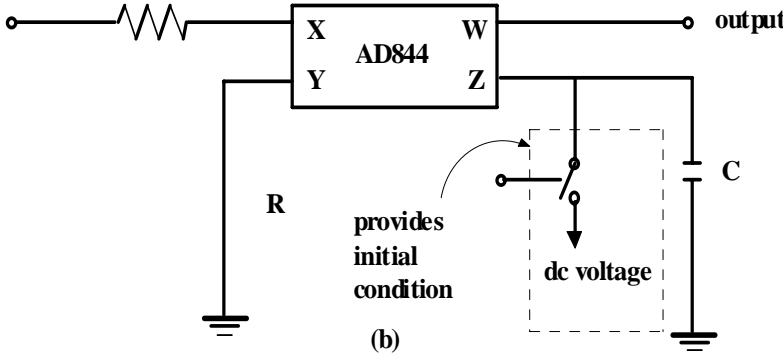


embodying the features of CCll+ is shown in (Fig. 3) whose terminal characteristics are written as:

$\left.\begin{array}{l}i_{y}=0 \\ v_{x}=v_{y} \\ i_{z}=i_{x} \\ v_{w}=v_{z}\end{array}\right\}$

The current at terminal $Z$ thus depends only on the input current $i_{x}$ at terminal $X$ which may be injected directly at $\mathrm{X}$, or it may be produced by the copy of the input voltage $v_{y}$, from terminal $Y$, acting across the impedance connected at $X$. The voltage $v_{w}$ at $W$ tracks the voltage $v_{z}$ at terminal $Z$. By convention, positive is taken to mean $i_{x}$ and $\mathrm{i}_{\mathrm{z}}$ both flowing simultaneously towards or away from the conveyor (Fig. 3). An integrator circuit employing current feedback amplifier (Mahattanakul \& Toumazou, 1996) and current conveyors (Makris \&Toumazou, 1990; Nandi \& Ray, 1993) have been proposed. An integrator circuit implemented with AD844 (Fig. 3) with the grounded capacitor is depicted (Fig. 4) wherein the circuitry used to enforce the initial condition does not pose problem to IC circuit designers.

The proposed scheme of generating sinusoidal oscillations using AD844 configured as the positive second generation current conveyor $(\mathrm{CCll}+)$ with a unity gain voltage amplifier (buffer) is shown in Fig. 5 . The circuit built around IC AD844 marked as 'INT 1' as shown under the dotted lines box is a positive integrator with a time constant $R_{1} C_{1}$ followed by a negative integrator with time constant $R_{2} C_{2}$ built around $A D 844$ marked as ' INT 2'. The switches placed across $C_{1}, C_{2}$ and $C_{F}$ are obtained from CMOS quad SPST analog switches DG201 with the pin numbers as depicted in the Fig. 5 . The op amp is configured as voltage comparator and provides a dc output voltage to the control pins of DG201 sufficient enough to operate the switches as per the truth table (Table 1).

The circuit shown in Fig. 5 operates as follows:

Before the power is switched ON, switches $\mathrm{SW}_{1}, \mathrm{SW}_{2}$ and $\mathrm{SW}_{3}$ are all in ON position (Table 1). However, immediately after the power is switched on, short circuit across $C_{F}$ is lifted (Table 1 ) and voltage $V_{F}$ across $C_{F}$ starts increasing exponentially with time constant of $R_{F}$ $\mathrm{C}_{\mathrm{F}}$. During this interval, however, switches SW1 and SW2 are closed giving $\mathrm{V}_{\mathrm{C} 1}=0 \mathrm{~V}$ (initial condition, i.e. $(d V / d t)_{t=0}$ and $\mathrm{V}_{\mathrm{C} 2}=\mathrm{V}_{\mathrm{Z} 1} \quad($ initial condition, i.e. $\left.\left.V\right|_{t=0}=V_{Z 1}\right)$. When $V_{F}$ exceeds $V_{Z 1}$, output of the op amp switches to positive high giving signal to $S W_{1}$ and $\mathrm{SW}_{2}$ to open. At this stage, the two integrators start functioning and output cosine waveform is generated with the peak amplitude of $\mathrm{V}_{\mathrm{Z} 1}$ (initial condition put on $\mathrm{C}_{2}$ ) and the frequency of oscillations $\omega$ is given by:
Vol. 3 No. 6 (June 2010)

ISSN: 0974- 6846

$$
\omega^{2}=\frac{1}{R_{1} R_{2} C_{1} C_{2}}
$$

The circuit shown in Fig. 5 was implemented in the laboratory with IC AD844 from analog devices and CMOS analog switches DG201. The resistors and capacitors used in the circuit were accurate to $\pm 5 \%$ and $\pm 10 \%$, respectively. The oscillograms at frequencies $8 \mathrm{KH}_{\mathrm{z}}$ and $227 \mathrm{KH}_{\mathrm{z}}$ are shown in (Fig. 6) respectively. Note that the peak amplitude can be varied by $\mathrm{V}_{\mathrm{Z} 1}$ using a simple voltage divider across zener diode and the frequency of oscillations is controlled either by $R\left(R_{1}\right.$ or $\left.R_{2}\right)$ or $C\left(C_{1}\right.$ or $\mathrm{C}_{2}$ ). The scheme is suitable for frequencies below $1 \mathrm{MH}_{Z}$. The frequency range could be extended using high frequency analog switches (Premont \& Abouchi, 1998).

Acknowledgement

The author thanks the UGC of India for the financial support under the grant no. F.10 - 4/97 (SR - 1).

References

1. Khan Anwar A, Bimal S, Dey KK and Roy SS (2002) Current conveyor based $\mathrm{R}$ and $\mathrm{C}$ - multiplier circuits. Int. J. Electronics Comm. (AEU). 56, 1-5.

2. Khan Anwar A, Bimal S, Dey KK and Roy SS (2005) Novel RC sinusoidal oscillator using second generation current conveyor. IEEE Trans. Inst. Meas. 54(6), 2402-2406.

3. Mahattanakul J and Toumazou C (1996) A theoretical study of the stability of high frequency current feedback op - amp integrator. IEEE Trans. Circuits Syst. 143, 2 -12.

4. Makris CA and Toumazou C (1990) High frequency, precision integrators using current conveyor compensation techniques. IEEE Int. Symp. on Circuits \& Systems. 1, 291-294.

5. Nandi R and Ray SB (1993) precise realization of current mode integrator using current conveyor. Elec. Let. 29, 1152-1153.

6. Premont C and Abouchi NA (1998) current conveyor based high frequency analog switch. IEEE Trans. Circuits Sys.145, 298-300.

7. Sedra AS, Roberts GW and Ghon F (1990) The current conveyors: history, progress and new results. Proc. Inst. Elect. Engg. Part G, 137, 78-87.

8. Singh (1980) Noval sinusoidal oscillators employing grounded capacitors. Elec. Lett. 16,757-758.

9. Svoboda JA, Mcgory L and Webb S (1991) Applications of a commercially available current conveyor. Int. J. Electronics. 70, 159-164.

10. Toumazou C, Lidgey FJ and Haigh DG (1990) Analog IC design: The current - mode approach. London, P.Peregrinus.

11. Wilson B (1990) Recent developments in current conveyors and current mode circuits. Proc. Inst. Elect. Engg. Part G, 137, 63-77.
Anwar A.Khan et al. Indian J.Sci.Technol. 